\title{
Polycystic Ovary Syndrome and its Relationship with Infertility and its Management
}

\author{
Z JAHAN $^{\mathrm{a}}, \mathrm{KE}$ WING $^{\mathrm{b}}$
}

\begin{abstract}
:
Polycystic ovary syndrome (PCOS) is the most common and treatable endocrine dysfunction in fertile women. The pathophysiology of PCOS involves primary defects in the hypothalamic-pituitary axis, insulin secretion and action, and ovarian function.Studies show 20-40 percent of female first-degree relatives of women with PCOS also have the syndrome.Genetic studies have identified a link between PCOS and disordered insulin metabolism and hyperinsulinemia.PCOS is characterized by hyperandrogenism, irregular ovulatory cycle and metabolic derangement, including glucose intolerance and hyperinsulinemia. Hyperandrogenism is a clinical hallmark of PCOS.In women with PCOS, Ovulation problems are usually the primary cause
\end{abstract}

Introduction:

Polycystic ovary syndrome (PCOS) is the most common endocrine dysfunction in fertile women, PCOS characterized by heterogeneous presentation of hyperandrogenism, ovulatory dysfunction, and polycystic ovarian morphology $(\mathrm{PCOM})^{1}$. The disorder can be morphological (polycystic ovaries) or predominantly biochemical (hyperandrogenemia). Hyperandrogenism, a clinical hallmark of PCOS, can cause inhibition of follicular development, micro cysts in the ovaries, anovulation, and irregularity of menstruation ${ }^{2}$. This syndrome can also be associated

a. Dr. Zakia Jahan, MBBS, MPH, Director of Center for Human Development. 37157 2nd Street, Apt \# 35, Jackson Heights, NY 11372

b. Kirsten Elyse wing, MSW, MPH, 645 Acker Pl NE, Washington, DC 20002, United States

Address of Correspondence: Dr. Zakia Jahan, MBBS, MPH, Director of Center for Human Development. 37157 2nd Street, Apt \# 35, Jackson Heights, NY 11372, E-mail: zakiamonzur@gwmail.gwu.edu, Phone: 1-646-851-3824

Received: 25 June, 2020

Accepted: 22 October, 2020 of infertility. PCOS is the most common cause of anovulatory infertility; 90-95\% of women seeking treatment for infertility have PCOS. PCOS may cause higher risk for infertility, type 2 diabetes, high blood pressure, and endometrial cancer. The most common symptoms are irregular period, weight gain, acne, and excessive facial and body hair. PCOS has no cure but there are multiple treatments that can reduce symptoms. Life style modification includingdiet and exercise, have shown a positive influence on women with PCOS.

Key words: polycystic ovary syndrome (PCOS), infertility, anovulation, hyperandrogenism, hyperinsulinemia, lifestyle modification.

(J Bangladesh Coll Phys Surg 2021; 39: 53-58)

DOI: https://doi.org/10.3329/jbcps.v39i1.50458

with metabolicissues including obesity, insulin resistance (found in $60-80 \%$ of women with PCOS) 3 .

According to the National Institutes of Health (NIH) Office of Disease Prevention, PCOS affects approximately 5 million women of childbearing age in the U.S

Symptoms of PCOS usually begin during the teenage years around the start of menstruation and can be mild or severe. The most common symptoms are irregular period, weight gain, acne, and excessive facial and body hair. The severity of the symptoms varies from woman to woman. It is not uncommon for women with PCOS to have normal appearing ovaries but still have an imbalance in hormone levels ${ }^{5}$.

Though PCOS has a high prevalence, there is still a lack ofwell-defined diagnostic criteriaand specific diagnostic tests. Thismay lead to confusion in diagnosis.A patient may present to any one of several providers: an internal medicine, gynecologist, dermatologist, or endocrinologist due to its multifaceted and varied manifestations of the disorder ${ }^{6}$. 
Multiple morbidities are associated with PCOS including metabolic syndrome, obesity, impaired glucose tolerance, depression, obstructive sleep apnea (OSA), endometrial cancer, and non-alcoholic fatty liver disease/ non-alcoholic steato hepatitis (NAFLD/NASH), most important is women's fertility related disorder like infertility ${ }^{7}$. PCOS has also shown to increase Insulin resistance in women, which can cause Type 2 Diabetes $^{6}$.

\section{Strategy for Literature Search:}

Articles related to PCOS, specially emphasizing how it causes infertility were retrieved from different journals, web pages and repositories including PubMed by using key words, polycystic ovary syndrome, infertility, anovulation, hyperandrogenism, hyperinsulinemia and lifestyle modification. From them 40 papers were included to prepare this manuscript.

\section{Diagnostic criteria:}

Polycystic Ovarian Disease (Stein-Leventhal Syndrome) was initially diagnosed it in 1935 by American gynecologists Irving F. Stein, Sr., and Michael L. Leventhal ${ }^{7}$.

The European Society of Human Reproduction and Embryology/American Society for Reproductive Medicine Rotterdam consensus (ESHRE/ASRM) developed and supports the diagnosis of PCOS, requiring two of three features: anovulation or oligo-ovulation, clinical or biochemical hyperandrogenism, and polycystic ovarian morphology $(\mathrm{PCOM})^{8}$.

\section{Causes and Risk factor:}

PCOS can be described as an oligogenic disorder due to the interaction of several genetic and environmental factors that determine the heterogeneous, clinical, and biochemical phenotype ${ }^{9}$. Studies show 20-40 percent of female first-degree relatives of women with PCOS also have the syndrome. Intrauterine exposure to testosterone may increases the later development of PCOS. Additionally, environmental factors implicated in PCOS, such as obesity, can be exacerbated by poor dietary choices and physical inactivity. Obesity is present in 30-75 percent of women with PCOS. There is an increased risk of anovulation and consequent subfertility in case of obese women with $\operatorname{PCOS}^{10}$. The current literature suggests the clustering of PCOS in families resembles an autosomal dominant pattern ${ }^{11}$.It is also theorized that infectious agents and toxins may also play a role in $\operatorname{PCOS}^{11}$.

\section{Pathogenesis:}

The pathophysiology of PCOS involves primary defects in the hypothalamic-pituitary axis, insulin secretion and action, and ovarian function ${ }^{11}$.
Women with PCOS have an increase in the frequency of GnRH pulses; shorter pulses preferentially promote the production of luteinizing hormone $(\mathrm{LH})$ this results in a decrease in the production of follicle stimulating hormone (FSH). Normally, progesterone is released from the corpus luteum following ovulation. Progesterone acts to slow GnRH pulsation. In PCOS, a decrease in ovulatory events may cause a decrease in circulating progesterone ${ }^{10}$.

Some research has suggested that the secretion of $\mathrm{LH}$ from the anterior pituitary gland increases the stimulatory effect on the ovarian theca cells and may lead to the raised levels of androgenic hormones and irregular or absent ovulation. The level of follicle stimulating hormone (FSH) is reduced with respect to $\mathrm{LH}$, which reduces the reaction to aromatize the androgen hormones to estrogen. As a result, there is less estrogen available and ovulation may not be able to occur ${ }^{12}$.

Clinical signs of PCOS include elevated LH and GnRH levels, whereas FSH levels are muted or unchanged. As a result of the increase in GnRH, stimulation of the ovarian thecal cells, in turn, produces more androgens ${ }^{13}$. Approximately $25 \%$ of patients with PCOS have elevated prolactin levels ${ }^{14}$. Studies have reported that thecal cells in patients with PCOS produce higher amounts of testosterone, progesterone, and 17-hydroprogesterone than in normal patients. These cells have been altered in PCOS patients whose cytochrome P450 (CYP) 11A, 3-HSD2, and CYP17 genes exhibit elevated levels ${ }^{15}$.

Genetic studies have identified a link between PCOS and disordered insulin metabolism and hyperinsulinemia ${ }^{16}$. Insulin resistance affects 50-70 percent of women with $\operatorname{PCOS}^{17}$.Elevated levels of insulin in the portal circulation also serve to decrease circulating sex hormone-binding globulin levels, thus resulting in higher levels of free androgens ${ }^{18}$. Hyperandrogenism, a clinical hallmark of PCOS, can cause inhibition of follicular development, micro cyst formation in the ovaries, which can cause anovulation and menstrual irregularity ${ }^{19}$.

Researchers at the Icahn School of Medicine at Mount Sinai in New York City, New York found that PCOS is linked with rare genetic variants in the gene DENND1A which is involved in testosterone production. This analysis carried out a genetic, family-based analysis using whole genome sequencing. This testing could behelpful to detect the syndrome earlier ${ }^{20}$. 


\section{Clinical Features:}

PCOS is a hormonal disorder and is comorbid with other diseases. It is also a common cause of infertility among women ${ }^{21}$.

Symptoms of PCOS include hirsutism, acne, alopecia, elevated androgen levels, and the prevalence of polycystic ovaries on pelvic ultrasound $^{22}$. Other symptoms include irregular menstrual cycles, pelvic pain, Acanthosis Nigricans, skin tags, and enlarged ovaries containing multiple cysts $^{23}$.

\section{Effects of PCOS on Infertility:}

The United States' Office on Women's Health (OWH) noted that PCOS affects 5 to 10 percent of women aged 15 to 44 years. They describe PCOS as a "common and treatable cause of infertility"24.

PCOS typically related to hormonal imbalances, insulin resistance, and metabolic abnormalities, which significantly increases the risk of infertility, type 2 diabetes, and cardiovascular disease (CVD) ${ }^{25}$.PCOS is the most common cause of ovulatory infertility.Approximately 90 to 95 percent of women seeking treatment for infertility have $\mathrm{PCOS}^{26}$.

Women often learn they have PCOS after seeking infertility treatment. Most women with PCOS have increased levels of luteinizing hormone and reduced levels of follicle-stimulating hormone (FSH), coupled with elevated levels of androgens and insulin resulting in fertility issues ${ }^{27}$.

These imbalances can manifest as oligo menorrhea or amenorrhea (infrequent or lack of menstruation). Underproduction of estrogen and overproduction of androgens (testosterone, dehydroepiandrosterone, and androstenedione) by the ovaries can result in a number of additional clinical features, including tiny cysts on the surface of the ovaries (polycystic) as well as hair and skin symptoms ${ }^{28}$.

PCOS can affect a person's fertility in different ways. In women who have polycystic ovary syndrome, or PCOS, there is an imbalance in female sex hormones. The imbalance may prevent the development and release of mature eggs. Without a mature egg, neither ovulation nor pregnancy can occur. Even if ovulation occurs, an imbalance in hormones may prevent the development of uterus lining that can prevent implantation of the mature egg. Due to unbalanced hormones, ovulation and menstruation can be irregular. Unpredictable menstrual cycles can also make it difficult for women to conceive ${ }^{24}$.

Due to complicating factors involved in normal follicular development, follicular growth becomes arrested as follicles reach a diameter of four to eightmillimeters. Ovulation does not ensue due to a dominant follicle does not develop ${ }^{29}$. If a healthy egg isn't released, it can't be fertilized by sperm, meaning that women who are affected by PCOS may not be able to get pregnant. PCOS can cause menstrual period loss or irregularity. This can be one of the first signs of $\mathrm{PCOS}^{30}$.

\section{Management and Treatment Options:}

There is a myriad of treatments for PCOS. Lifestyle modification, including a healthy diet and exercise, weight loss is essential and considered as the first lineof treatment for PCOS.Diets with lower carbohydrates and a reduced glycemic load are recommended. Exercise is also recommended in PCOS patients; at least 30 minutes of moderate exercise three times per week ${ }^{31}$. Losing 10 percent of body weight may help menstrual cycle become more regular and predictable.Losing weight may help women with PCOS to become pregnant ${ }^{30}$. Weight problems can contribute to inflammation which can inhibit fertility. One study found a healthy diet, like the Mediterranean Diet whichconsists of large amounts of fresh vegetables and moderate amounts of fruit, fish, in addition to whole grains, beans, nuts, and seeds decreased symptoms of PCOS. Studies also show HFCS (high-fructose corn syrup) can interfere with ovulation and fertility ${ }^{32}$.

Weight loss among those with PCOS resulted in the restoration of spontaneous ovulation and higher fertility rates. An aggressive approach to reduce weight, including pharmacological strategies and the use of contraception and high-dose folic acid was proposed for obese women before planning a pregnancy for better pregnancy outcome ${ }^{33}$.

One study found an increase in vitamin D intake is beneficiary because it decreases testosterone. Other research has shown Vitamin D maintains inflammatory markers like C-reactive protein and decreases oxidative stress in women with PCOS that is helpful to decrease side effects for women with $\operatorname{PCOS}^{32}$.

\section{Treatment options:}

Regulation of irregular menstruation- low dose combined OCP (oral contraceptive preparation) will 
result regular shedding of the endometrium and create artificial cycle.Meaning, it will control the irregular menstrual cycle ${ }^{34}$.

For ovulation induction the drug of choice for women with PCOS is Clomiphene citrate, which is a selective estrogen receptor modulator. The dose can be started from $50 \mathrm{mg}$ per cycle to a maximum dose of $150 \mathrm{mg}$ /day. Before considering further therapy, up to six ovulatory cycles should continue with clomiphene citrate ${ }^{35}$.Afterapplying the maximum dose of $150 \mathrm{mg} /$ day, failure to ovulation induction is considered clomiphene resistant. Failure to achieve pregnancy after six ovulatory cycles is classified as a clomiphene failure ${ }^{36}$.

Antidiabetic agent, metformin is a safe method to regulate irregular menstruation.It decreases insulin resistance and reduce circulating androgen level beside insulin sensitivity, and lower androgen. It can also be used to improve fertility and it improve cardiovascular health in adolescents with $\mathrm{PCOS}^{34}$.

Aromatase inhibitors are used for women who are clomiphene resistance or not candidate for clomiphene or gonadotrophins ${ }^{34}$.Aromatase inhibitors has negative feedback on hypothalamus, meaning it blocks the conversion testosterone and androstenedione to estradiol and estrogen, decrease in estrogenic activity this mechanism allowing for an increase in the release of $\mathrm{FSH}^{37}$.

According to ESHRE/ASRM the second line therapies for ovulation induction is laparoscopic ovarian drilling (LOD) is considered. During LOD there is four to ten holes are made in the surface and the stroma of the ovary, bya laser or electrocautery. This is usually performed on women suffering from infertility who haveclomiphene resistantLOD ${ }^{35}$.

Women who have no indication for surgery, a less invasive treatment like gonadotropin approach is preferred. LOD is preferred for patients who are not able to follow the rules of gonadotropin therapy such as regular and frequent follow-upvisits and who have other indications for surgery ${ }^{38}$.

The 2008 Thessaloniki ESHRE/ASRM-Sponsored PCOS Consensus Workshop Group recommended In-vitro fertilization (IVF) as third-line treatment therapy for the management of infertility ${ }^{35}$.Egg freezing can be another option for young women who are concerned about possible infertility due to $\operatorname{PCOS}^{39}$
Besides weightmanagement having multi vitamin containing Vitamin B12, zinc, magnesium and folate is essential. Drinking enough water throughout the day and having sound sleep are also vital ${ }^{40}$.

\section{Conclusion:}

Although PCOS is the most common cause of infertility, if caught early it can be treated with relatively simple measures including diet and lifestyle changes. Once thought to be just an endocrine disorder, the disease has since proven to be a multifaceted and complex disorder. PCOS is a metabolic, psychological, and lifestyle disorder. Women who have high levels of stress and anxiety often suffer from PCOS and should seek treatment for those psychological symptoms as well the physiological systems.

PCOS has no cure however, early interventions can reduce complications. Treatment of symptoms such as irregular periods, acne, excess hair, and elevated blood sugar through both pharmacological and lifestyle changes can greatly increase a woman's chance of getting pregnant.

PCOS has no cure but multiple treatment therapy can reduce symptoms and disorder. Early seeking of medical attention can reduce complication. However, there is way treat symptoms such as irregular periods, acne, excess hair, and elevated blood sugar through both pharmacological and lifestyle changes.

\section{References:}

1. Palomba S, Santagni S, Falbo A, La Sala GB. Complications and challenges associated with polycystic ovary syndrome: current perspectives [Internet]. International journal of women's health. Dove Medical Press; 2015 [cited 2019Jul8]. Available from: https:/www.ncbi.nlm.nih.gov/pmc/articles/PMC4527566/ https://doi.org/10.2147/IJWH.S 70314 , PMid:26261426 PMCid:PMC4527566

2. Lin LH, Barracat MC, Gustavo AR, et al Androgen receptorgene polymorphism and polycystic ovary syndrome. Int JGynaecol obstet. 2013;; 120:115-18

3. Carmina E, Oberfield SE, Lobo RA Am J Obstet Gynecol. The diagnosis of polycystic ovary syndrome in adolescents.. 2010 Sep; 203(3):201.e1-5. https:// www.ncbi.nlm.nih.gov/pmc/articles/PMC4341818/ https://doi.org/10.1016/j.ajog.2010.03.008 PMid:20435290

4. Ndefo UA, Eaton A, Green MR. Polycystic ovary syndrome: a review of treatment options with a focus on pharmacological approaches. P T. 2013;38 (6):336-355. 
5. Polycystic ovary syndrome (PCOS): A Guide for parents. Parents Articles. 30 June 2016.

6. Sheehan MT. Polycystic ovarian syndrome: diagnosis and management. Clin Med Res. 2004;2(1):13-27. ht tps://doi.org/10.3121/cm r.2.1.13 PMid:15931331 PMCid:PMC1069067

7. Rasquin Leon LI, Mayrin JV. Polycystic Ovarian Disease (Stein-Leventhal Syndrome) [Updated 2018 Nov 18]. In: StatPearls [Internet]. Treasure Island (FL): StatPearls Publishing; 2019 Jan-

8. Bani Mohammad M, Majdi Seghinsara A. Polycystic Ovary Syndrome (PCOS), Diagnostic Criteria, and AMH. Asian Pac J Cancer Prev. 2017;18(1):17-21. Published 2017 Jan 1. doi:10.22034/APJCP.2017.18.1.17

9. Xita N, Georgiou I, Tsatsoulis AEur J. The genetic basis of polycystic ovary syndrome Endocrinol. 2002 Dec; 147(6):717-25, https://doi.org/10.1530/ eje.0. 1470717, PMid:12457445

10. Ragini Srinivasan, Sultan Chaudhry, Eric Wong. Polycystic ovarysyndrome. J Obstet Gnnaecol Can. 2010; 32(5): 423-28

11. Diamanti - Kandarakis E, kandarakis H, Legro RS. The role of genes and environment in the etiology of PCOS. Endocrine.2006;30:19-26. https://doi.org/ 10.1385/ENDO:30:1:19

12. Smith Y. Polycystic Ovary Syndrome Pathogenesis. News Medical life sciences. August (4), 2016.

13. Urbanek M. The genetics of polycystic ovary syndrome. Natl Clin Pract Endocrinol Metab. 2007;3:103-111. https://doi.org/10.1038/ncpendmet0400 PMid: 17237837

14. Marx TL, Mehta AE. Polycystic ovary syndrome: Pathogenesis and treatment over the short and long term. Cleve Clin J Med. 2003;70(1):31-33. 36-41, 45. https://doi.org/10.3949/ccjm.70.1.31 PMid:12549723

15. Strauss JF. Some new thoughts on the pathophysiology and genetics of polycystic ovary syndrome. Ann NY Acad Sci. 2003;997:42-48. https://doi.org/10.1196/annals.1290.005 PMid:14644808

16. Adam H. Balen: Polycystic ovary Syndrome and Secondary amenorrhea. Dewhurst's Text book of obstetrics and Gynecology for post graduates. 17th ed. Black well publishing.2007: 377-98.

17. Susan M. Sirmans and Kristen, A pate. Epidemiology, Diagnosisand management of polycystic ovary syndrome. Dove Medicalpress Limited. USA. 2014; 6: 1-13. https://doi.org/10.2147/ CLEP.S37559, PMid:24379699 PMCid:PMC3872139
18. Nestler, J.E., Powers, L.P., Matt, D.W., Steingold, K.A., Plymate, S.R., Rittmaster, R.S.etal. A direct effect of hyperinsulinemia on serum sex hormone-binding globulin levels inobese women with the polycystic ovary syndrome. J Clin Endocrinol Metab. 1991; 72: 83-89, https://doi.org/ 10.1210/jcem-72-1-83, PMid:1898744

19. Lin LH, Barracat MC, Gustavo AR, et al Androgen receptorgene polymorphism and polycystic ovary syndrome. Int JGynaecol obstet. 2013; 120:115-18 https://doi.org/10.1016/j.ijgo.2012.08.016 PMid:23182796

20. Magowan J. Gene behind major cause of women's infertility found. Bio news. 2019;

21. Ndefo, U. A., Eaton, A., \& Green, M. R. (2013). Polycystic ovary syndrome: a review of treatment options with a focus on pharmacological approaches. P \&T : a peer-reviewed journal for formulary management, 38(6), 336-355.

22. Azziz R, Carmina E, Dewailly D, et al. Position statement: Criteria for defining polycystic ovary syndrome as a predominantly hyper-androgenic syndrome. An Androgen Excess Society guideline. J Clin EdocrinolMetab. 2006;91:4237-4245, https://doi.org/ 10.1210/jc.2006-0178, PMid:16940456

23. Ndefo UA, Eaton A, Green MR. Polycystic ovary syndrome: a review of treatment options with a focus on pharmacological approaches [Internet]. P \&T: a peer-reviewed journal for formulary management. MediMedia USA, Inc.; 2013 [cited 2019Jul13]. Available from: https://www.ncbi.nlm.nih.gov/pmc/ articles/PMC3737989/\#b13-ptj3806336

24. Pietro MA. Polycystic ovary syndrome and fertility: Causes, symptoms, and effects [Internet]. Medical News Today. MediLexicon International; 2019

25. National Institutes of Health. NIH Evidence-Based Methodology Workshop on Polycystic Ovary Syndrome: executive summary, 2012.

26. Teede H, Deeks A, Moran L. Polycystic ovary syndrome: a complex condition with psychological, reproductive and metabolic manifestations that impacts health across the lifespan. BMC Medicine 2010;8:41, https://doi.org/ 10.1186/1741-7015-8-41 PMid:20591140 PMCid:PMC2909929

27. Haqq L, McFarlane J, Dieberg G, Smart N. Effect of lifestyle intervention on the reproductive endocrine profile in women with polycystic ovarian syndrome: a systematic review and meta-analysis. Endocr Connect 2014;3:36-46, https://doi.org/10.1530/ EC-14-0010, PMid:24488490 PMCid:PMC3938041

28. Salley KES, Wickham EP, Cheang KI, Essah PA, Kargane NW, Nestler JE. Glucose intolerance in 
polycystic ovary syndrome: a position statement of the Androgen Excess Society. J Clin Endocrinol Metab2007;92:4546-4556, https://doi.org/10.1210/ jc.2007-1549, PMid:18056778

29. Brassard M, AinMelk Y, Baillargeon JP. Basic infertility including polycystic ovary syndrome. Med Clin North Am. 2008;92:1163-1192. https://doi.org/ 10.1016/j.mcna.2008.04.008, PMid:18721657

30. I Have PCOS -- Can I Still Get Pregnant? [Internet]. [cited 2019Jul19]. Available from: https://www.webmd. com/infertility-and-reproduction/polycystic-ovary-sy ndrome-fertility\#1

31. PCOS and Infertility - What It Is, Symptoms \& Treatment: CCRM Fertility [Internet].Colorado Center for Reproductive Medicine. [cited 2019Jul23]. Available from: https://www.ccrmivf.com/ pcos-infertility/

32. Head K. The Most Frequent Cause of Female Infertility? PCOS. Thorne;2018

33. Orio F, Tafuri D, Ascione A, et al. Lifestyle changes in the management of adulthood and childhood obesity. Minerva Endocrinol. 2014

34. Nahar, K. (2019). Polycystic Ovary Syndrome in Teenage and Young Women. Journal of Bangladesh College of Physicians and Surgeons, 37(2), 78-82. https://doi.org/10.3329/jbcps.v37i2.40564
35. Thessaloniki ESHRE/ASRM-Sponsored PCOS Consensus Workshop Group Consensus on infertility treatment related to polycystic ovary syndrome. Fertil Steril. 2008;89(3):505-522, https://doi.org/ 10.1016/ j.fertnstert.2007.09.041, PMid:18243179

36. Costello MF, Misso ML, Wong J, et al. The treatment of infertility in polycystic ovary syndrome: a brief update. Aust N Z J Obstet Gynaecol. 2012; 52:400-403. https://doi.org/10.1111/ j.1479-828X.2012.01448.x, PMid:22639834

37. Casper RF, Mitwally MF. Use of the aromatase inhibitor letrozole for ovulation induction in women with polycystic ovarian syndrome. Clin Obstet Gynecol. 2011;54(4):685-695. https://doi.org/ 10.1097/GRF.0b013e3182353d0f, PMid:22031258

38. Perales-Puchalt A, Legro RS. Ovulation induction in women with polycystic ovarysyndrome. Steroids. 2013;78:767-772. https://doi.org/10.1016/ j.steroids. 2013.05.005, PMid:23707553

39. Gordon S. 1st Gene Linked to Polycystic Ovary Syndrome [Internet]. 2019 [cited 2019Jul23]. Available from: https://www.webmd.com/ women/ news/20190501/1st-gene-linked-to-polycystic-ovarysyndrome\#2

40. Prakash S. PCOS: A lifestyle disorder. The Telegraph 2018 